\title{
Orthonasal and retronasal detection thresholds of 26 aroma compounds in a model alcohol-free beer: effect of threshold calculation method
}

\section{Article}

Accepted Version

Creative Commons: Attribution-Noncommercial-No Derivative Works 4.0

Piornos, J. A., Delgado, A., de La Burgade, R. C. J., Methven, L., Balagiannis, D. P., Koussissi, E., Brouwer, E. and Parker, J. K. (2019) Orthonasal and retronasal detection thresholds of 26 aroma compounds in a model alcohol-free beer: effect of threshold calculation method. Food Research International, 123. pp. 317-326. ISSN 0963-9969 doi:

https://doi.org/10.1016/j.foodres.2019.04.034 Available at https://centaur.reading.ac.uk/83299/

It is advisable to refer to the publisher's version if you intend to cite from the work. See Guidance on citing.

To link to this article DOI: http://dx.doi.org/10.1016/j.foodres.2019.04.034

Publisher: Elsevier

All outputs in CentAUR are protected by Intellectual Property Rights law, including copyright law. Copyright and IPR is retained by the creators or other copyright holders. Terms and conditions for use of this material are defined in the End User Agreement. 


\section{www.reading.ac.uk/centaur}

\section{CentAUR}

Central Archive at the University of Reading

Reading's research outputs online 


\section{Orthonasal and retronasal detection thresholds of 26 aroma}

\section{2 compounds in a model alcohol-free beer: Effect of threshold}

\section{3 calculation method}

4

5 José A. PIORNOS ${ }^{1}$, Alexia DELGADO ${ }^{1}$, Rémi C.J. DE LA BURGADE ${ }^{1}$, Lisa METHVEN ${ }^{1}$, Dimitrios

6 P. BALAGIANNIS ${ }^{1}$, Elisabeth KOUSSISSI ${ }^{2, \dagger}$, Eric BROUWER ${ }^{2}$, Jane K. PARKER ${ }^{1, *}$

7

8

${ }^{1}$ Department of Food and Nutritional Sciences, University of Reading, RG6 6AP, UK.

$9{ }^{2}$ Heineken Supply Chain BV, Global Innovation \& Research, Burgemeester Smeetsweg, 1, 2382 PH

10 Zoeterwoude, The Netherlands.

*Corresponding author: E-mail address: j.k.parker@reading.ac.uk

${ }^{\dagger}$ Current address: Department of Wine, Vine and Beverage Sciences, University of West Attica, Ag. 


\section{Abstract}

23 Detection thresholds are used routinely to determine the odour-active compounds in foods. The 24 composition of a food matrix, such as hydrophobicity or solids content, has an impact on the release 25 of flavour compounds, and thus on thresholds. In the case of beer, thresholds determined in alcoholic beer may not be the same for alcohol-free beer (AFB). Therefore, the aim of this study was to determine detection thresholds for aroma compounds typically found in beer within a model AFB. The model was designed to match the sugar concentration and $\mathrm{pH}$ of an AFB brewed by a cold contact process. Thresholds were measured using a 3-AFC procedure and calculated using either Best

30 Estimate Threshold (BET) method or by logistic regression. Moreover, an algorithm for the removal 31 of false positives was applied to adjust the assessors' raw responses. Retronasal thresholds were generally lower than orthonasal. Those calculated by BET were significantly higher $(\mathrm{p}<0.05)$ than those from logistic regression, and removal of false positives also produced significantly higher thresholds than those from raw data. The use of logistic regression has the advantage of providing the mathematical model describing the behaviour of the group. The results from this study can be used to better understand the role of flavour compounds in AFB and the effect of the calculation method to prevent under- or overestimated results.

42 Keywords: alcohol-free beer, orthonasal threshold, retronasal threshold, best estimate threshold, logistic regression, method comparison 
Detection thresholds are commonly used in flavour science as a measure of the potency of flavour compounds. They are defined as the minimum concentration of a flavour compound at which its presence can be detected in a food or beverage, but this concept has also been applied to other research fields, such as air pollution (Leonardos, Kendall, \& Barnard, 1969). Flavour compounds can be ranked according to their odour activity by comparing their concentration in a food and their detection threshold. Odour activity values are an important tool in flavour research and have been used to identify key odorants in a wide variety of foods, including virgin olive oil (Guth \& Grosch, 1993), rape honey (Ruisinger \& Schieberle, 2012), and wheat beer (Langos, Granvogl, \& Schieberle, 2013). It is also recognised that flavour compounds may contribute to the overall aroma of a food at subthreshold concentrations due to synergistic effects with other odorants (Kishimoto, Noba, Yako, Kobayashi, \& Watanabe, 2018).

Aroma detection thresholds depend on many variables and are difficult to predict, if not impossible. Apart from the natural differences in sensitivity of humans to different flavour compounds (Schranz, Lorber, Klos, Kerschbaumer, \& Buettner, 2017), other factors affect perception too. One source of difference relates to the way that individuals are exposed to the odorant, either orthonasally or retronasally. When sniffing a food, flavour molecules have to be released from the food matrix to the air and then travel through the nasal cavity to reach the olfactory mucosa (Espinosa Díaz, 2004). This corresponds to orthonasal perception of the odorant, whereas in the case of retronasal perception the flavours are released in the mouth and cross the nasopharynx via the posterior nares before reaching the nasal cavity and olfactory mucosa.

The release of the flavour compounds from the food matrix is the starting point for both orthonasal and retronasal sensory experiences. Along with other factors, such as temperature, the composition of the food matrix plays a key role in the release of volatiles compounds (Hansson, Andersson, \& Leufvén, 2001). For example, the orthonasal detection threshold for the sweaty, cheesy flavour compound 3-methylbutanoic acid in water has been reported to be $490 \mu \mathrm{g} / \mathrm{L}$ (Czerny et al., 2008), whereas in sunflower oil the reported threshold was only $22 \mu \mathrm{g} / \mathrm{L}$ (Reiners \& Grosch, 1998). Other 
food components, such as sugars or ethanol, also have a significant effect on the release of volatiles from the food to the air phase. Perry and Hayes (2016) concluded that thresholds determined in one food matrix should not be translated to a different food system. Such assumptions can lead to underor overestimation of the real potency of flavour chemicals in foods when comparing their concentration with inappropriate threshold values.

Alcoholic and alcohol-free beers are a good example of two similar food matrices where different composition may affect volatile release. Lager beers usually contain $5 \%$ alcohol by volume (ABV) and low remaining fermentable sugars, i.e. glucose, fructose, sucrose, maltose and maltotriose. There are studies in the literature reporting detection thresholds of flavour compounds in Lager beers (Meilgaard, 1975; Saison, De Schutter, Uyttenhove, Delvaux, \& Delvaux, 2009). However, thresholds determined in this alcohol-containing matrix may not be applicable to alcohol-free beers (AFB). In the case of AFB, the absence of alcohol (below $0.05 \% \mathrm{ABV}$ ), and the presence of non-fermented sugars from wort in beers brewed by cold contact fermentation, are likely to make the release of flavour compounds from this matrix different from alcoholic Lager beers.

The sensory method most commonly employed in determining thresholds is the three-alternative forced choice (3-AFC) discrimination method. However, even where this sensory method is applied consistently across studies, another source of variation in published threshold values is due to the calculation method used. The most commonly used calculation method is Best Estimate Threshold (BET) (Czerny et al., 2008; Plotto, Margaría, Goodner, \& Baldwin, 2008; Plotto, Margaría, Goodner, Goodrich, \& Baldwin, 2004). According to ISO 13301:2002, this method consists of calculating the geometrical mean of "the highest concentration missed and the next higher concentration". This is done for every assessor's response and the average of the group is then calculated, this being the final threshold value. This ISO standard discloses some of the disadvantages of this method, such as the calculation of thresholds out of the range of concentrations assessed when an assessor's threshold falls above or below the range evaluated. Moreover, BET values do not give any further information about the behaviour of the group for concentrations of the odorant other than the calculated threshold. In recent years, authors have started using an alternative calculation approach by means of psychometric 
sigmoid functions. These functions consider the probability of perceiving the presence of the flavour compound (i.e. the probability of identifying the correct sample during the experiment) against compound concentration. When using this approach, the threshold is often defined as the concentration at which there is a $50 \%$ probability of detecting the flavour compound (Lawless, 2010). Several mathematical models have been used for this purpose, such as Weibull distribution, logistic function (Hough, Methven, \& Lawless, 2013) or the Hill equation, often used in biochemistry (Perry \& Hayes, 2016). By using this modelling approach, concentrations other than $50 \%$ probability can be easily calculated, and these may be useful in certain cases, for instance, to avoid detection of off-notes in foods by very sensitive consumers (Lawless, 2010). By comparing thresholds calculated using BET and fitting the data to the Hill equation, Perry and Hayes (2016) observed differences between both methods, BET values being lower than detection thresholds (DTs) calculated from the Hill equation in most of the experiments reported. The authors did not discuss the differences between both algorithms that led to the different threshold values. Furthermore, false positives, i.e. correct answers given by chance, could have an effect in the final threshold values. Hough et al., (2013) proposed a threshold calculation method by logistic regression using different functions, which included the application of an algorithm for the adjustment of false positives. The weight of these false positive responses was not evaluated nor their impact on the threshold value. Certainly, the false positives are expected to influence the final threshold values.

It is reasonable to consider that the release of flavour compounds from AFBs brewed by cold contact fermentation is not comparable to water or Lager beer-like systems (usually $5 \%$ ethanol in water). Considering the impact of alcohol on flavour release, it was hypothesised that orthonasal and retronasal DTs from the AFB would be different to those previously published in alcoholic beers. Furthermore, the second hypothesis of this study was that the threshold calculation method had a significant effect on the final value, as well as the presence of false positives. Hence, the aim of this study was to determine orthonasal and retronasal detection thresholds in a model AFB of aroma compounds typically found in beer. The effect of the calculation method (BET and logistic regression) and the impact of false positives on the final threshold values were tested too. 


\section{Materials and methods}

\subsection{Materials}

Carbonated water (Sparkling spring water, Aldi Stores Ltd., UK), sucrose (> 90 \%, Silver Spoon, UK), fructose (> $90 \%$, Tate \& Lyle, UK), and glucose powder (> $90 \%$, Thornton \& Ross Ltd., UK) were purchased at a local store. $\mathrm{C}$ 放 Sweet ${ }^{\mathrm{TM}}$ glucose syrup (composition in dry base: $5 \% \mathrm{w} / \mathrm{w}$ glucose, $75 \% \mathrm{w} / \mathrm{w}$ maltose, $10 \% \mathrm{w} / \mathrm{w}$ maltotriose, $10 \% \mathrm{w} / \mathrm{w}$ unspecified components) was donated by Cargill (Manchester, UK).

\subsection{Aroma compounds}

The following aroma compounds were purchased from Sigma-Aldrich (purity in parenthesis): acetaldehyde ( $\geq 99 \%$ ), acetic acid ( $\geq 99.5 \%), 2,3$-butanedione (97\%), butanoic acid ( $\geq 99 \%)$, dimethyl sulfide ( $\geq 99 \%$ ), 5(or 2)-ethyl-4-hydroxy-2(or 5)-methyl-3(2H)-furanone (homofuraneol, $96 \%$ ), Z-4-heptenal ( $\geq 98 \%$ ), 3-hydroxy-4,5-dimethyl-2(5H)-furanone (sotolone, $10 \%$ in propylene glycol), 4-hydroxy-2,5-dimethyl-3(2H)-furanone (furaneol, $\geq 98 \%$ ), methional ( $\geq 97 \%$ ), 2'methoxyacetophenone (99\%), 2-methoxy-4-methylphenol ( $\geq 98 \%$ ), 2-methoxyphenol ( $\geq 99 \%)$, 2 methoxy-4-vinylphenol ( $\geq 98 \%$ ), 2-methylbutanal ( $\geq 95 \%)$, 3-methylbutanal ( $\geq 97 \%)$, 3methylbutanoic acid (99\%), 3-methyl-1-butanol ( $\geq 98 \%$ ), methylpropanal ( $\geq 98 \%$ ), 2methylthiophene (98\%), 2,3-pentanedione ( $\geq 96 \%$ ), phenylacetaldehyde (10\% in ethanol), 2phenylacetic acid ( $\geq 99 \%)$, 2-phenylethanol ( $\geq 99 \%$ ), vanillin ( $\geq 97 \%)$, 4-vinylphenol (10\% in propylene glycol). All were food grade except 2'-methoxyacetophenone and 2-methylthiophene.

\subsection{Preparation of the model alcohol-free beer}

A model beer was prepared to match the sugar content of an alcohol-free beer brewed following a standard cold contact fermentation procedure, bottling and pasteurisation carried out at Heineken's pilot brewery (Zoeterwoude, The Netherlands). First, a five-fold concentrated solution of sugars was prepared in tap water. Then, one part of the sugar solution was diluted into four parts of carbonated water, reaching the final concentration of sugars: $7.2 \mathrm{~g} / \mathrm{L}$ glucose, $2.1 \mathrm{~g} / \mathrm{L}$ fructose, $0.6 \mathrm{~g} / \mathrm{L}$ sucrose, $26.9 \mathrm{~g} / \mathrm{L}$ maltose and 3.6 g/L maltotriose. In parallel, a stock solution of odorants was prepared in 
absolute ethanol (Sigma-Aldrich, UK). Then, $400 \mu \mathrm{L}$ stock solutions containing the odorant (absolute ethanol for blanks) were added to one litre of model beer. The final $\mathrm{pH}$ of the model was 4.50 and the final ethanol content was $0.04 \%$.

\subsection{Sensory methodology}

For each compound, the aim was to collect threshold data from 24 trained and experienced sensory assessors. To achieve this, allowing for absences, there was a pool of 33 assessors ( 8 men, 25 women, ages 25 to 60). The assessors were recruited from the flavour and sensory groups of The University of Reading, all of whom had experience in describing a wide range of aroma chemicals. Preliminary sensory experiments were carried out in order to establish the range of concentrations for the threshold experiments, as well as to familiarise the panellists with the aroma chemicals. For 7 out of 26 compounds for orthonasal assessment and 2 for retronasal assessment, only 12 assessors were available. The experiments were designed following a three-alternative forced choice (3-AFC) methodology (ISO13301:2002). Each sample (10 mL) was presented in a screw-capped 27-mL clear glass vial (height $72 \mathrm{~mm}$, internal diameter $23 \mathrm{~mm}$ ) at a temperature between 9 and $14{ }^{\circ} \mathrm{C}$. Six concentrations of each compound were presented in ascending order, each being 3 times more concentrated than the previous sample. Each concentration was presented along with two blank samples per level. Within each set of three, the order of blanks and the sample was balanced and randomised ( $\mathrm{AAB}, \mathrm{ABA}$, or $\mathrm{BAA})$ across the panellists, and all samples were coded with 3-digit random numbers. During each one-hour sensory session, three compounds were presented to the panel. After sniffing all the samples to assess orthonasal perception, the samples were presented for a second time, in a random but balanced order, and the panellists were asked to taste them for retronasal perception. The vials were presented uncapped to avoid interference with aroma from the headspace when assessing the samples for retronasal perception. Compusense Cloud (Compusense Inc., Guelph, ON, Canada) was used to guide panellists during the study as well as to collect responses. The experiments were carried out in individual sensory booths (controlled temperature $18-20^{\circ} \mathrm{C}$ ) at the Sensory Science Centre of The University of Reading.

\subsection{Data analysis}


179 In order to remove false positives, i.e. positive responses given by chance, the methodology published 180 by Hough et al. (2013) was followed. Responses were classified into four different cases exemplified 181 in Table 1:

- Case 1: Negative response. If the panellist could not identify the sample containing the aroma compounds, this remained as "no" in all cases.

- Case 2: "Yes before or next to no". This applies to all positive responses before a negative answer, and also those just after a negative response (i.e. those first in a row of correct answers). In these cases, first, the proportion of discriminators $\left(\mathrm{P}_{\mathrm{d}}\right)$ was calculated (Lawless, 2010) (Eq. 1):

$$
\mathrm{P}_{\mathrm{d}}=\frac{\mathrm{P}_{\text {corr }}-\mathrm{P}_{\text {chance }}}{1-\mathrm{P}_{\text {chance }}} \quad \text { Eq. } 1
$$

where $\mathrm{P}_{\text {corr }}$ is the proportion of correct answers at a concentration level and $\mathrm{P}_{\text {chance }}$ is the probability of getting a correct answer by chance (in 3-AFC tests, this is $1 / 3$ ). Then, the ratio $\mathrm{P}_{\mathrm{d}} / \mathrm{P}_{\text {corr }}$ was calculated and compared with a random number $\mathrm{X}$ from 0.000 to 1.000 generated using the function "RAND". If $\mathrm{P}_{\mathrm{d}} / \mathrm{P}_{\text {corr }}<\mathrm{X}$, the original positive response was corrected and replaced by a negative answer.

- Case 3: "Second yes after last no". In this case, the same procedure as in case 2 was followed, although the $\mathrm{P}_{\text {chance }}$ used in this case was $1 / 9$. This was because this positive response is the second in a row, so the chance of getting two correct answers is $(1 / 3) \times(1 / 3)$.

- Case 4: "Third and further yes after no". The probability of choosing a third correct answer by chance is $(1 / 3) \times(1 / 3) \times(1 / 3)$. This is below $5 \%$, so it was assumed that these were real positives and consequently kept as positives. ProPlus). 
BETs were calculated from raw and adjusted data according to the procedure reported in ISO 13301:2002. BETs for each assessor and compound were calculated as the geometric mean of the highest concentration for a negative response and the next concentration. In the case where an assessor's response was either negative or positive for all the concentrations presented, the BET was calculated as the geometrical mean using the next concentration in the series (up or down, respectively) which had not been tested.

\subsubsection{Logistic regression}

The raw and adjusted data were fitted to the logistic function (Eq. 2) using XLSTAT 2012:

$$
\mathrm{P}_{\mathrm{c}}(\ln \mathrm{C})=\frac{1}{1+\mathrm{e}^{-(\alpha+\beta \ln C)}} \quad \text { Eq. } 2
$$

Where $\mathrm{P}_{\mathrm{c}}$ is the probability of a correct answer, $\alpha$ is the factor that sets the displacement of the curve along the abscissa axis, and $\beta$ is the steepness factor. The detection threshold was considered as the concentration at which the probability of correct answer was 0.50 .

\subsubsection{Statistical analysis}

Thresholds calculated by BET and logistic regression, from raw data and after removal of false positives (adjusted data), were compared aiming to determine significant differences between these four different methods. T-test for paired samples $(\alpha=0.05)$ was applied to the logarithms of the threshold values grouped into methods, i.e. not distinguishing between orthonasal and retronasal thresholds for this purpose.

\section{Results}

\subsection{Orthonasal and retronasal thresholds in a model AFB}

Table 2 shows the orthonasal detection thresholds for 26 aroma compounds in a model alcohol-free beer, calculated by the four different methods. The overall range of values obtained for different compounds was noticeably broad, from below $1 \mu \mathrm{g} / \mathrm{L}$ to more than $100,000 \mu \mathrm{g} / \mathrm{L}$. The highest orthonasal DTs, (those over 1,000 $\mu \mathrm{g} / \mathrm{L}$, i.e. $1 \mathrm{ppm})$, were found for acetic acid $(131,000$ 391,000 $\mu \mathrm{g} / \mathrm{L}), 2$-methylthiophene (1,732-11,800 $\mu \mathrm{g} / \mathrm{L})$, and 2-phenylacetic acid (1,174-5,830 $\mu \mathrm{g} / \mathrm{L})$. 
On the other hand, the lowest values (those below $1 \mu \mathrm{g} / \mathrm{L}$, i.e. $1 \mathrm{ppb}$ ) were found for Z-4-heptenal (0.0035-0.022 $\mu \mathrm{g} / \mathrm{L})$, methional (0.19-0.68 $\mu \mathrm{g} / \mathrm{L})$, and 3-methylbutanal (0.31-0.64 $\mu \mathrm{g} / \mathrm{L})$. A similar scenario was observed for these compounds when assessed for retronasal perception. Table 3 shows the results for retronasal detection thresholds for 20 aroma compounds. The compounds with the highest retronasal detection thresholds were acetic acid (22,100-104,000 $\mu \mathrm{g} / \mathrm{L})$, 4-vinylphenol (90.04,210 $\mu \mathrm{g} / \mathrm{L})$, and 2-phenylacetic acid (12.6-1,690 $\mu \mathrm{g} / \mathrm{L})$. As for orthonasal perception, methional $(0.040-1.78 \mu \mathrm{g} / \mathrm{L})$ and 3-methylbutanal $(0.22-0.74 \mu \mathrm{g} / \mathrm{L})$ exhibited the lowest retronasal threshold values. Orthonasal threshold values were higher than retronasal for most of the compounds evaluated. The only exceptions were dimethyl sulfide and 3-methyl-1-butanol, for which retronasal detection thresholds were higher than orthonasal. For other compounds (methional, 3-methylbutanal, and 4vinylphenol), the difference between orthonasal and retronasal thresholds was less apparent as it was dependent on the method used to calculate the threshold.

\subsection{Comparison of calculation methods}

In this study, two different threshold calculation methods were used, as well as an algorithm for the removal of false positives. As shown in Tables 2 and 3, both orthonasal and retronasal detection thresholds were affected by the calculation method (BET or logistic regression) and the removal of false positives (raw and adjusted data). Figure 1 shows the comparison plots for the different calculation approaches, where orthonasal and retronasal thresholds from each method are plotted against each other. Thresholds calculated from adjusted data were higher than those from raw data, independently of the compound assessed, this increase being higher in the case of the logistic regression than the BET. This can be observed when comparing the trendline equations (Figure 1a and $1 \mathrm{~b}$ ), where, although the slopes were very close to one, the lines do not pass through zero and there is a significant intercept. The interpretation of these trendline equations and the meaning of this intercept is complicated by the fact that the thresholds are plotted on a log plot. The trendline equations were expressed in the following terms: $\ln \mathrm{DT}_{1}=\mathrm{a} \times \ln \mathrm{DT}_{2}+\ln (\mathrm{b})$ where $\mathrm{a} \approx 1$ and the intercept is $\ln (\mathrm{b})$. Using the standard rules of logarithms, $\mathrm{DT}_{1}=\mathrm{DT}_{2} \times \mathrm{b}$, so b represents the constant 
ratio between the methods. The intercept from the graph gives $\ln (\mathrm{b})$, so the constant ratio is the exponential of the intercept, or $\exp (b)$.

In the case of the adjustment of false positives, the intercept in Figure 1a $(+1.4698)$ was higher than in Figure $1 \mathrm{~b}(+0.3792)$. This means that the values from logistic regression and adjusted data were, on average, 4.3 times (i.e. exp $(+1.4698))$ higher than those from raw data, whereas this difference was only 1.5 times $(\exp (+0.3792))$ in the case of BET. Differences were also found between BET and logistic regression methodologies from the same sets of data (raw and adjusted data) (Figures 1c and 1d). In both cases, BET produced higher threshold values than logistic regression and the difference was greater for raw data (intercept +1.5825 , ratio 4.9 ) than adjusted data (intercept +0.4804 , ratio 1.6 ). In order to identify significant differences between methods, t-tests for paired samples were applied. P-values from these tests showed significant differences $(\mathrm{p}<0.05)$ between the results from BET and logistic regression $\left(\mathrm{p}=1.4 \times 10^{-14}\right.$ for BET raw vs. logistic regression raw; $\mathrm{p}=1.2 \times 10^{-9}$ for BET adjusted vs. logistic regression adjusted), as well as for those calculated from raw and adjusted data for both methods $\left(\mathrm{p}=7.2 \times 10^{-27}\right.$ for BET raw vs. BET adjusted; $\mathrm{p}=7.1 \times 10^{-21}$ for logistic regression raw vs. logistic regression adjusted). Surprisingly, thresholds from logistic regression from adjusted data and standard BET from raw data were not significantly different $(\mathrm{p}=0.31)$.

\subsection{Logistic regression for the calculation of thresholds}

Supplementary Tables A.1 and A.2 show the parameters that define the logistic models for the probability of a correct answer (i.e. correct identification of the aroma compound) against the logarithm of the concentration of the compound. The logistic model used here is defined by two parameters: $\alpha$ sets the displacement along the $\mathrm{x}$-axis, and $\beta$ is the steepness factor. According to Eq. 2, a lower value of $\alpha$ is translated in a higher value for the inflexion point of the sigmoidal curve, whereas higher values of $\beta$ give steeper curves. For both orthonasal and retronasal studies, the adjustment of the data for the removal of false positives produced a decrease in the $\alpha$ parameter, which resulted in a displacement of the curve towards the right and, thus, higher thresholds. The steepness factor $\beta$ was also affected by the adjustment of the data because the $\beta$-values from adjusted data were higher than those from raw data. An exception to this trend was the orthonasal model for Z- 
4-heptenal, for which the $\alpha$-factor was higher after the removal of false positives. Despite this, the orthonasal detection thresholds for these compounds were still higher because the effect of the $\alpha$ factor was compensated for by a higher $\beta$-factor.

The removal of false positives also affected the goodness of fit of the logistic model. The adjustment of the data produced an increase of the pseudo- $\mathrm{R}^{2}$ values in all cases, for both orthonasal and retronasal models (Supplementary Tables A.1 and A.2). Furthermore, the confidence interval for the thresholds calculated using this method were considerably narrower after the removal of false positives (Figure 2). For example, the error bar for the retronasal detection threshold of vanillin was reduced from three orders of magnitude to only one (Figure $2 b$ ). For a few compounds (2methylbutanal and 3-methyl-1-butanol for orthonasal, and methional, 2-methoxy-4-methylphenol, 2phenylacetic acid, and 4-vinylphenol for retronasal detection thresholds) confidence intervals could not be calculated properly when using raw data because the calculation method could not converge to a solution after 100 iterations. This issue was resolved after the removal of false positives, when confidence intervals could be calculated in all cases.

\section{Discussion}

\subsection{Threshold calculation method}

Thresholds calculated by BET and logistic regression were found to be significantly different $(p<0.05)$ for both orthonasal and retronasal data. Logistic regression generated lower threshold values from both raw and adjusted data. Psychometric functions take into consideration all the positive responses along the entire range of concentrations. On the other hand, BET only considers positive answers that are not followed by negative answers. This makes logistic curves displaced towards the left to lower concentrations, resulting in lower threshold values. Previous studies have compared the standardised BET method with logistic regression. Perry and Hayes (2016) found that thresholds from BET were lower than those calculated by using logistic regression. These results, which may seem to be contradictory to those from the present study, might be explained by the fact that these authors used an equation model that it is restricted from $33 \%$ to $100 \%$ probabilities on the 
ordinate axis. In our study, we did not use a restricted model, as shown in Eq. 2, so the probability of correct answer can vary from $0 \%$ to $100 \%$. In our opinion, the use of an algorithm for the removal of false positives already discards the correct answers given by chance, so the restriction at $33 \%$ chance should not be necessary anymore. When using restricted models, it is common to define the threshold at $66.6 \%$ chance as the middle point of the curve (between $33.3 \%$ and $100 \%$ ). This might be another reason why these authors obtained higher threshold values with logistic regression. Lawless (2010) also used $66.6 \%$ probability as the corrected $50 \%$ detection level following a similar reasoning.

The effect of the removal or correction of false positives was also covered in the present study. As shown above, threshold values increased significantly after the application of this algorithm. In previous studies, differences between BET raw and logistic regression adjusted thresholds were observed. Hough et al. (2013) reported that the BET method using raw data produced lower thresholds than logistic regression from adjusted data. This was associated with the fact that in logistic regression the adjustment of the responses pushed the threshold upwards, whereas this data treatment was not applied when using BET. In our study, there was not a clear trend when comparing these two sets of thresholds. Not all BET raw thresholds were lower than the corresponding logistic regression adjusted threshold (Figure 1e) and on average the results from these methodologies were not significantly different $(\mathrm{p}=0.31)$. This demonstrated that logistic regression along with the removal of false positives is a methodology comparable to the standardised BET, with the advantage of providing further information such as the mathematical model describing the response of the group at different concentrations of an aroma compound.

\subsection{Orthonasal thresholds}

In the literature, perception thresholds are available for different aroma compounds determined in a variety of matrices, e.g. water (Czerny et al., 2008), air (Schranz et al., 2017), and beer (Meilgaard, 1975, 1982; Saison et al., 2009). In Figure 3, those found in the literature (diamonds) for water, $9.4 \%$ ethanol or beer are compared to those from the present study (horizontal bars) for both orthonasal (Fig. 3a) and retronasal (Fig. 3b) perception. Full details of these threshold values from the literature 
can be found in Appendix B. Before plotting them, all the thresholds units were converted into $\mu \mathrm{g} / \mathrm{L}$

334 for comparison.

335 The impact of ethanol on aroma release was demonstrated instrumentally by Perpète and Collin

336 (2000), who observed higher retention of 2-methylbutanal and 3-methylbutanal when increasing the concentration of ethanol from 0 to $5 \%$ in an aqueous solution. This was explained by the 'cosolvent' effect of ethanol in water, thus increasing the solubility of these aldehydes and reducing their partition coefficients between the water/ethanol solution and the air (Tsachaki et al., 2008). However, Figure 3a shows that the literature detection thresholds which had been determined in $9.4 \%$ ethanol fell within the same range as those determined in water in 4 out of 5 cases.

The role of sugar on flavour release has been studied more extensively. Perpète and Collin (2000) demonstrated that the presence of sugars in beer produced an increase in the release of 2- and 3methylbutanal, up to a maximum sugar concentration of $40 \mathrm{~g} / \mathrm{L}$. Tsitlakidou, Van Loey, Methven, \& Elmore (2019), and Hansson et al. (2001) also showed this salting-out effect of non-polar compounds in soft drinks when sugar increased from $\sim 40-150 \mathrm{~g} / \mathrm{L}$ and 200-600 g/L, respectively. Bredie, Mottram, \& Birch (1994) also showed an increase in volatility with added glucose (200 g/L) for hydrophobic compounds such as menthol and limonene in a maltodextrose solution, but no effect with the more polar compounds (3-methylbutyl acetate and 2,3-butanedione). Banavara, Rabe, Krings, \& Berger (2002) modelled flavour release and predicted a salting-out effect for most compounds. However, experimentally they reported that the effect was much less than predicted, and not statistically significant for more polar compounds. These literature studies in accord with our data, which cover a range of more polar compounds, rather than the terpenes and longer chain aldehydes which showed the biggest salting-out effects in these literature studies. On average the more polar compounds in our study (6: homofuraneol, 8: sotolone, 9: furaneol, 12: 2-methoxy-4-methylphenol, 14: 2-methoxy-4-vinylphenol, 25: vanillin, and 26: 4-vinylphenol) showed no evidence of salting-out and presented higher orthonasal thresholds than those from the literature (Fig. 3a). This may be due to the interaction between the sugars and these more polar volatiles. 
The effect of carbonation on flavour release has been studied, particularly in relation to champagne. Pozo-Bayón, Santos, Martín-Álvarez, \& Reineccius (2009) showed an increase in aroma release with carbonation but stressed the importance of the physicochemical character of the volatiles, showing the most hydrophobic, most volatile compounds were affected the most. Saint-Eve et al. (2009) looked at the effect of adding $10 \mathrm{~g} / \mathrm{L}$ sucrose on aroma release of carbonated beverages. Carbonation had by far the bigger effect and increased volatile release, but added sucrose had no impact on aroma release in the carbonated samples. Our results did not show a corresponding decrease in aroma threshold with carbonation, but surface activity, bubble size and bubble frequency are important parameters which we could not readily control.

\subsection{Retronasal thresholds}

Retronasal thresholds were much scarcer in the literature, most of them being comparable to our results (Fig. 3b). In this study, retronasal thresholds for 2,3-butanedione (3), butanoic acid (4), 2 methoxy-2-vinylphenol (14), 3-methyl-1-butanol (18) and 2-phenylacetic acid (23) were lower than those from the literature, whereas furaneol (9) showed a higher threshold in the AFB model. Apart from the matrix effect, the differences between thresholds from the literature and our results could be due to the diversity of methodologies employed. This includes differences in calculation method (BET, interpolation using probability vs. concentration graphs), number of panellists and sample presentation (triangle, 3-AFC, duo-trio test, sets of samples presented in either ascending or descending concentrations) (Guadagni, Buttery, \& Okano, 1963; Langos et al., 2013; Rothe, Wölm, Tunger, \& Siebert, 1972). All too often, authors of threshold studies do not fully specify the details of their studies, this making comparisons less valid. This was demonstrated in a comprehensive literature search, and summarised in Appendix B, which shows thresholds in the literature and the main characteristics of the sensory study.

Comparing the results for orthonasal and retronasal perception, retronasal DTs tended to be lower than orthonasal for most of the compounds assessed, independently of the data treatment (Tables 2 and 3). The reason behind this does not seem to be very clear. Retronasal perception is a more complex process which also involves changes in temperature of the foodstuff, dilution with saliva, 
binding to mucous membranes in mouth and tongue, increase of air/food surface area and the mixing

387 effect of swallowing (Taylor \& Roozen, 1996). Due to the higher complexity of the retronasal

388 pathway, Espinosa Díaz (2004) hypothesised a higher efficiency of the orthonasal pathway, thus requiring lower concentrations of odorants for the same odour intensity as the retronasal pathway. On the other hand, the opposite behaviour was observed by Voirol and Daget (1986) for vanillin and citral, which was related to a higher concentration of these odorants in the vapor phase when put in the mouth, as well as the influence of other non-chemical interactions. From the results of the current study it appears that most of the compounds studied corresponded with the latter theory as their retronasal thresholds were lower. For the compounds that were the exceptions to this, there is no clear reason why they were all detected at lower levels orthonasally. Dimethyl sulfide is a highly volatile compound and hence it is perhaps unsurprising that its orthonasal DT would be lower. However, this was not the case for the other three less volatile compounds (homofuraneol, furaneol, and 3-methyl-1butanol). The relatively low $\log \mathrm{P}$ values of these four compounds did not seem to be the reason behind this behaviour either, since other compounds with similar $\log$ P values (methylpropanal), 2methoxyphenol and 2-methylbutanal) did not show the same effect.

\section{Conclusions}

402 Orthonasal and retronasal detection thresholds of 26 and 20 aroma compounds, respectively, are reported in a model AFB for the first time. Four different methodologies for threshold calculation were applied and compared, elucidating the role of the calculation procedure in the final threshold value. Threshold values were found to be method-dependent (BET and logistic regression), as well as affected by the presence of false positives or correct answers given by chance. Although BET is a standard commonly used threshold calculation method, logistic regression is recommended for the additional information extracted from the data. Additionally, data treatment for the removal of false positives is strongly recommended in order to obtain a more realistic mathematical model.

410 The determination of perception thresholds in the correct matrix is crucial for estimating the potency

411 of flavour compounds in conditions closer to the real beverage. After a comprehensive literature

412 research, we have shown that for many of the compounds studied, our results in a model AFB were 
413 comparable to those reported in water. However, a group of polar compounds (mainly furanones and

414 phenols) consistently showed higher orthonasal detection thresholds in the model AFB compared to

415 water (literature values). Comparison of threshold values from different studies may be very risky due

416 to the lack of consistency of the methods for threshold determination so it is strongly recommended

417 that the experimental setup, matrix in which the odorant was presented and threshold calculation

418 method are all extracted from the primary source wherever possible to ensure they are appropriate.

419 The results reported in the present study can be of great importance for the brewing industry when

420 studying the aroma composition of alcohol-free beers brewed by cold contact fermentation. The

421 market for alcohol-free beers is currently undergoing huge growth worldwide, and the determination

422 of perception thresholds is essential to understand the role of flavours compounds and their

423 contribution to the overall aroma.

\section{Acknowledgments}

425 This study has been funded by Heineken Supply Chain BV. We would also like to acknowledge

426 Compusense Inc. for provision of the sensory software under an academic consortium agreement as

427 well as all the panellists that participated in this study.

\section{Conflicts of interest}

429 The authors declare no conflicts of interest. 
Banavara, D. S., Rabe, S., Krings, U., \& Berger, R. G. (2002). Modeling dynamic flavor release from water. Journal of Agricultural and Food Chemistry, 50(22), 6448-6452. https://doi.org/10.1021/jf020232c

Bredie, W. L. P., Mottram, D. S., \& Birch, G. G. (1994). Aroma binding in maltodextrose solutions. In H. Maarse \& D. G. Van der Heij (Eds.), Trends in Flavour Research (pp. 139-143). New York: Elsevier. Schieberle, P. (2008). Re-investigation on odour thresholds of key food aroma compounds and development of an aroma language based on odour qualities of defined aqueous odorant solutions. European Food Research and Technology, 228(2), 265-273. https://doi.org/10.1007/s00217-0080931-x

Espinosa Díaz, M. (2004). Comparison between orthonasal and retronasal flavour perception at different concentrations. Flavour and Fragrance Journal, 19(6), 499-504. https://doi.org/10.1002/ffj.1475

Guadagni, D. G., Buttery, R. G., \& Okano, S. (1963). Odour thresholds of some organic compounds associated with food flavours. Journal of the Science of Food and Agriculture, 14(10), 761-765. https://doi.org/10.1002/jsfa.2740141014

Guth, H., \& Grosch, W. (1993). Quantitation of Potent Odorants of Virgin Olive Oil by Stable-Isotope Dilution Assays. Journal of the American Oil Chemists' Society, 70(5), 513-518. Retrieved from https://link.springer.com/article/10.1007/BF02542586 from a soft drink-related model system. Food Chemistry, 72(3), 363-368. https://doi.org/https://doi.org/10.1016/S0308-8146(00)00243-0 
ISO 13301:2002. (n.d.). Sensory analysis - Methodology - General guidance for measuring odour,

459 flavour and taste detection thresholds by a three-alternative forced-choice (3-AFC) procedure.

460 Kishimoto, T., Noba, S., Yako, N., Kobayashi, M., \& Watanabe, T. (2018). Simulation of Pilsner-type 461 beer aroma using 76 odor-active compounds. Journal of Bioscience and Bioengineering, 126(3), 330338. https://doi.org/10.1016/J.JBIOSC.2018.03.015

Langos, D., Granvogl, M., \& Schieberle, P. (2013). Characterization of the Key Aroma Compounds in Two Bavarian Wheat Beers by Means of the Sensomics Approach. Journal of Agricultural and Food Chemistry, 61(47), 11303-11311. https://doi.org/10.1021/jf403912j forced-choice methods of limits. Journal of Sensory Studies, 25(3), 332-346. https://doi.org/10.1111/j.1745-459X.2009.00262.x

470 Chemicals. Journal of the Air Pollution Control Association, 19(2), 91-95. https://doi.org/10.1080/00022470.1969.10466465

472 Meilgaard, M. C. (1975). Flavor Chemistry of Beer. II. Flavor and threshold of 239 aroma volatiles. Master Brewers Association of the Americas Technical Quarterly, 12(3), 151-168. Composition. Journal of Agricultural and Food Chemistry, 30(6), 1009-1017. https://doi.org/10.1021/jf00114a002 
483 for key aroma components in an orange juice matrix: esters and miscellaneous compounds. Flavour and Fragrance Journal, 23(6), 398-406. https://doi.org/10.1002/ffj.1888 flavour thresholds for key aroma components in an orange juice matrix: terpenes and aldehydes.

Pozo-Bayón, M. Á., Santos, M., Martín-Álvarez, P. J., \& Reineccius, G. (2009). Influence of carbonation on aroma release from liquid systems using an artificial throat and a proton transfer reaction-mass spectrometric technique (PTR-MS). Flavour and Fragrance Journal, 24(5), 226-233. https://doi.org/10.1002/ffj.1934

Reiners, J., \& Grosch, W. (1998). Odorants of Virgin Olive Oils with Different Flavor Profiles. Journal of Agricultural and Food Chemistry, 46(7), 2754-2763. https://doi.org/10.1021/jf970940b Aromastoffen und ihre Nutzung zur Auswertung von Aromaanalysen. Die Nahrung, 16(5), 483-495. https://doi.org/https://doi.org/10.1002/food.19720160509

Ruisinger, B., \& Schieberle, P. (2012). Characterization of the key aroma compounds in rape honey by means of the molecular sensory science concept. Journal of Agricultural and Food Chemistry, 60, 4186-4194. https://doi.org/10.1021/acs.jafc.6b04499 Influence of composition ( $\mathrm{CO} 2$ and sugar) on aroma release and perception of mint-flavored carbonated beverages. Journal of Agricultural and Food Chemistry, 57(13), 5891-5898. https://doi.org/10.1021/jf900542j staling compounds to the aged flavour of lager beer by studying their flavour thresholds. Food 
507 Schranz, M., Lorber, K., Klos, K., Kerschbaumer, J., \& Buettner, A. (2017). Influence of the chemical 508 structure on the odor qualities and odor thresholds of guaiacol-derived odorants, Part 1: Alkylated, 509 alkenylated and methoxylated derivatives. Food Chemistry, 232, 808-819.

510 https://doi.org/10.1016/j.foodchem.2017.04.070

511 Taylor, A. J., \& Roozen, J. P. (1996). Volatile Flavor Release from Foods during Eating. Critical 512 Reviews in Food Science and Nutrition, 36(8), 765-784. https://doi.org/10.1080/10408399609527749

513 Tsachaki, M., Gady, A.-L., Kalopesas, M., Linforth, R. S. T., Athès, V., Marin, M., \& Taylor, A. J. 514 (2008). Effect of Ethanol, Temperature, and Gas Flow Rate on Volatile Release from Aqueous 515 Solutions under Dynamic Headspace Dilution Conditions. Journal of Agricultural and Food 516 Chemistry, 56(13), 5308-5315. https://doi.org/10.1021/jf800225y

517 Tsitlakidou, P., Van Loey, A., Methven, L., \& Elmore, J. S. (2019). Effect of sugar reduction on 518 flavour release and sensory perception in an orange juice soft drink model. Food Chemistry, 284, 519 125-132. https://doi.org/10.1016/j.foodchem.2019.01.070

520 Voirol, E., \& Daget, N. (1986). Comparative study of nasal and retronasal olfactory perception. LWT 521 Food Science and Technology, 19(4), 316-319. 
523 Figure 1. Comparison of methods. Natural logarithms of orthonasal and retronasal thresholds (in

$524 \mu \mathrm{g} / \mathrm{L}$ ) calculated by the different methodologies have been plotted, as well as the linear trend line

525 (red) and the line of equality (grey). BET raw: Best Estimate Threshold from raw data; BET adj: BET

526 from adjusted data (i.e. with false positives removed); LR raw: Logistic regression from raw data; LR

527 adj: Logistic regression with adjusted data.

528 Figure 2. Detection thresholds calculated by logistic regression showing confidence intervals $(\alpha=95 \%)$

529 for orthonasal (a) and retronasal (b) perceptions, "Confidence interval not available.

530 Figure 3. Comparison of orthonasal (a) and retronasal (b) detection thresholds determined in this study

531 and those found in the literature. Legend: Thresholds calculated by $(-)$ BET from raw data, $(-)$ BET

532 from adjusted data, (-) logistic regression from raw data, $(-)$ logistic regression from adjusted data;

533 thresholds from the literature: $(\diamond)$ in water and $(\diamond)$ other matrices $(9.4 \%$ ethanol in Fig. 3a or beer in

534 Fig. 3b). 
536 Table 1. Example of an assessor's response showing the different cases according to the algorithm for 537 the removal of false positives.

\begin{tabular}{lcccccc}
\hline Concentration, $\mu \mathrm{g} / \mathrm{L}$ & 1 & 3 & 9 & 27 & 81 & 273 \\
Assessor's response & no & yes & no & yes & yes & yes \\
Case & 1 & 2 & 1 & 2 & 3 & 4 \\
\hline
\end{tabular}

538 
Table 2. Orthonasal detection thresholds for 26 aroma compounds in an alcohol-free beer model system, calculated by four different methods.

\begin{tabular}{|c|c|c|c|c|c|c|c|}
\hline \multirow{3}{*}{ No. } & \multirow{3}{*}{ Compound } & \multirow{3}{*}{ Odour quality } & \multicolumn{5}{|c|}{ Orthonasal detection threshold, $\mu \mathrm{g} / \mathrm{L}$} \\
\hline & & & \multicolumn{2}{|c|}{ Logistic regression } & \multicolumn{2}{|c|}{ BET } & \multirow{2}{*}{$\begin{array}{l}\text { Threshold range in } \\
\text { literature, } \mu \mathrm{g} / \mathrm{L}\end{array}$} \\
\hline & & & Raw & Adjusted & Raw & Adjusted & \\
\hline 1 & acetaldehyde* & fruity, solvent & 14.5 & 45.8 & 37.5 & 49.3 & $11.7^{\mathrm{a}}-900^{\mathrm{b}}$ \\
\hline 2 & acetic acid & vinegar & 131,000 & 355,000 & 297,000 & 391,000 & $100^{c}-522,000^{d}$ \\
\hline 3 & 2,3-butanedione & caramel, raw meat, butter & 1.25 & 5.19 & 4.28 & 6.18 & $1^{\mathrm{e}}-15^{\mathrm{f}, \mathrm{g}}$ \\
\hline 4 & butanoic acid & cheese, sour, vomit & 907 & 2,080 & 1,390 & 2,190 & $1^{\mathrm{c}}-4,752^{\mathrm{d}}$ \\
\hline 5 & dimethyl sulfide* & vegetables, garlic, savoury & 13.4 & 48.4 & 47.2 & 89.5 & $0.24^{\mathrm{h}}-5^{\mathrm{b}}$ \\
\hline 6 & $\begin{array}{l}\text { 5-ethyl-4-hydroxy-2- } \\
\text { methyl-3(2H)-furanone } \\
\text { (homofuraneol) }\end{array}$ & candy floss, caramel & 35.3 & 102 & 83.2 & 131 & $1.15^{\mathrm{i}}$ \\
\hline 7 & Z-4-heptenal* & lamb fat, rancid oil, fish, rubber & 0.0035 & 0.016 & 0.014 & 0.022 & $0.0087^{\mathrm{e}}$ \\
\hline 8 & $\begin{array}{l}\text { 3-hydroxy-4,5-dimethyl- } \\
2(5 H) \text {-furanone (sotolone)* }\end{array}$ & curry, cooked sugar & 8.68 & 28.3 & 22.9 & 27.5 & $0.3^{\mathrm{g}, \mathrm{j}}-20^{\mathrm{i}}$ \\
\hline 9 & $\begin{array}{l}\text { 4-hydroxy-2,5-dimethyl- } \\
3(2 H) \text {-furanone (furaneol) }\end{array}$ & candy floss, strawberry & 49.4 & 148 & 87.3 & 158 & $1^{\mathrm{c}}-1,000^{\mathrm{c}}$ \\
\hline 10 & methional & boiled potato, metallic & 0.19 & 0.47 & 0.47 & 0.68 & $0.2^{\mathrm{g}, \mathrm{k}, 1}-1.8^{\mathrm{e}, \mathrm{j}}$ \\
\hline 11 & 2'-methoxyacetophenone & plastic, chemical, petrol & 688 & 2,260 & 2,880 & 3,300 & \\
\hline 12 & 2-methoxy-4-methylphenol & smoky, bacon, vanilla & 20.7 & 37.2 & 27.7 & 34.8 & $21^{\mathrm{e}}$ \\
\hline 13 & 2-methoxyphenol & smoky, chemical & 0.67 & 2.10 & 1.59 & 2.51 & $0.84^{\mathrm{e}}-3.39^{\mathrm{a}}$ \\
\hline 14 & 2-methoxy-4-vinylphenol & cloves, medicinal, bacon & 33.1 & 81.5 & 79.5 & 99.9 & $3^{\mathrm{m}}-100^{\mathrm{j}}$ \\
\hline 15 & 2-methylbutanal & fruity, sweet & 1.88 & 23.4 & 37.0 & 50.9 & $1.5^{\mathrm{e}}-5.6^{\mathrm{d}}$ \\
\hline 16 & 3-methylbutanal & malty, cheese & 0.31 & 0.61 & 0.47 & 0.64 & $0.15^{\mathrm{n}}-8^{\mathrm{b}}$ \\
\hline 17 & 3-methylbutanoic acid* & cheese, fruity, sour & 89.4 & 376 & 360 & 624 & $132^{\circ}-2,754^{d}$ \\
\hline 18 & 3-methyl-1-butanol & banana, nail polish remover & 23.3 & 89.0 & 96.5 & 127 & $203^{\mathrm{h}, \mathrm{p}}-4,750^{\mathrm{q}}$ \\
\hline 19 & methylpropanal & nutty, chemical & 1.01 & 4.32 & 3.44 & 5.69 & $0.49^{\mathrm{e}}-43.5^{\mathrm{o}}$ \\
\hline 20 & 2-methylthiophene* & vegetable stock, onion, solvent & 1,732 & 7,970 & 9,000 & 11,800 & \\
\hline 21 & 2,3-pentanedione* & butter, caramel & 3.06 & 12.9 & 13.7 & 18.0 & $30^{f}-500,000^{b}$ \\
\hline 22 & phenylacetaldehyde & rose, floral & 1.63 & 5.42 & 4.38 & 6.04 & $4^{\mathrm{k}, 1}-9^{\mathrm{b}}$ \\
\hline 23 & 2-phenylacetic acid & floral & 1,174 & 5,150 & 3,860 & 5,830 & $68^{r}-6,100^{e}$ \\
\hline 24 & 2-phenylethanol & floral, rose, bread dough & 569 & 1,880 & 1,580 & 3,000 & $140^{\mathrm{e}}-1,122^{\mathrm{a}, \mathrm{h}}$ \\
\hline
\end{tabular}




\begin{tabular}{|c|c|c|c|c|c|c|}
\hline vanillin & vanilla, caramel & 396 & 1,490 & 1,040 & 1,880 & $4.9^{\mathrm{j}}-53^{\mathrm{e}, \mathrm{s}}$ \\
\hline 4-vinylphenol & leather, chemical, plastic & 665 & 2,980 & 2,540 & 4,020 & $10.4^{\mathrm{a}}-78^{\mathrm{j}}$ \\
\hline
\end{tabular}

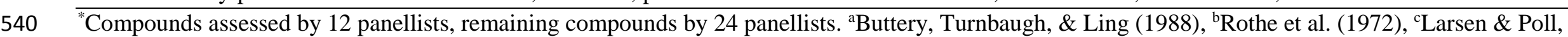

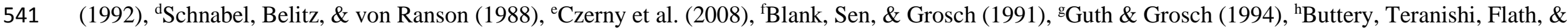

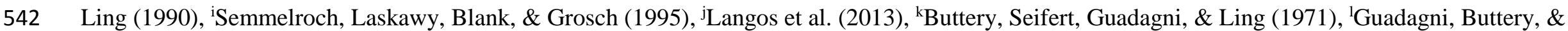

543 Turnbaugh (1972), ' Buttery, Guadagni, Ling, Seifert, \& Lipton (1976), " Guadagni et al. (1963), ${ }^{\circ}$ Amoore, Venstrom, \& Davis (1968), ${ }^{\mathrm{p} B a l d w i n, ~ S c o t t, ~}$

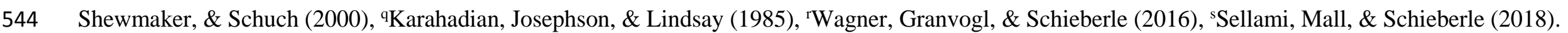

545 Full references in Appendix B. 
Table 3. Retronasal detection thresholds for 20 aroma compounds in an alcohol-free beer model system, calculated by four different methods.

\begin{tabular}{|c|c|c|c|c|c|c|c|c|}
\hline \multirow{3}{*}{ No. } & \multirow{3}{*}{ Compound } & \multirow{3}{*}{ Odour quality } & \multicolumn{6}{|c|}{ Retronasal detection threshold, $\mu \mathrm{g} / \mathrm{L}$} \\
\hline & & & \multicolumn{2}{|c|}{ Logistic regression } & \multicolumn{2}{|c|}{ BET } & \multicolumn{2}{|c|}{$\begin{array}{l}\text { Threshold range in } \\
\text { literature, } \mu \mathrm{g} / \mathrm{L}\end{array}$} \\
\hline & & & Raw & Adjusted & Raw & Adjusted & In water & In beer \\
\hline 2 & acetic acid & vinegar & 22,100 & 60,000 & 68,600 & 104,000 & $54,000^{\mathrm{a}}$ & $175,000^{\mathrm{h}}$ \\
\hline 3 & 2,3-butanedione & butter, dairy & 0.19 & 0.74 & 1.30 & 1.64 & $0.2^{b}-5^{c}$ & $17^{\mathrm{i}}-150^{\mathrm{h}}$ \\
\hline 4 & butanoic acid & cheese & 255 & 575 & 462 & 666 & $6,800^{\mathrm{a}}$ & $2,200^{\mathrm{h}}$ \\
\hline 5 & dimethyl sulfide* & sweet, vegetable, savoury & 39.3 & 74.8 & 56.7 & 81.7 & & $50^{\mathrm{h}}$ \\
\hline 6 & $\begin{array}{l}\text { 5-ethyl-4-hydroxy-2- } \\
\text { methyl-3(2H)-furanone } \\
\text { (homofuraneol) }\end{array}$ & candy floss, caramel & 27.9 & 134 & 131 & 238 & & \\
\hline 8 & $\begin{array}{l}\text { 3-hydroxy-4,5-dimethyl- } \\
\text { 2(5H)-furanone (sotolone)* }\end{array}$ & curry, molasses & 1.24 & 3.59 & 4.41 & 5.80 & & \\
\hline 9 & $\begin{array}{l}\text { 4-hydroxy-2,5-dimethyl- } \\
\text { 3(2H)-furanone (furaneol) }\end{array}$ & candy floss, strawberry & 81.5 & 270 & 190 & 300 & $30^{\mathrm{d}}$ & \\
\hline 10 & methional & boiled potato, metallic & 0.040 & 0.73 & 1.12 & 1.78 & $0.04^{\mathrm{c}, \mathrm{e}}$ & $4.2^{\mathrm{i}}-250^{\mathrm{h}}$ \\
\hline 12 & 2-methoxy-4-methylphenol & smoky, bacon, vanilla & 0.079 & 1.86 & 4.65 & 5.85 & & \\
\hline 13 & 2-methoxyphenol & vanilla, smoky & 0.42 & 0.99 & 1.21 & 1.91 & $0.75^{\mathrm{e}}$ & \\
\hline 14 & 2-methoxy-4-vinylphenol & cloves, medicinal, bacon & 1.90 & 8.33 & 24.2 & 30.4 & & $300^{\mathrm{h}}$ \\
\hline 15 & 2-methylbutanal & fruity, sweet, cheesy & 1.57 & 8.99 & 15.5 & 22.3 & $0.03^{b}-40^{f}$ & $45^{\mathrm{i}}-1,250^{\mathrm{h}}$ \\
\hline 16 & 3-methylbutanal & nutty, cheesy & 0.22 & 0.44 & 0.56 & 0.74 & $0.04^{b}-60^{f}$ & $600^{\mathrm{h}}$ \\
\hline 18 & 3-methyl-1-butanol & banana, cheese, fermented & 128 & 262 & 220 & 303 & $4,750^{\mathrm{f}}$ & $70,000^{\mathrm{h}}$ \\
\hline 19 & methylpropanal & chocolate & 0.16 & 0.86 & 1.65 & 2.17 & $0.006^{b}-180^{f}$ & $1,000^{\mathrm{h}}$ \\
\hline 22 & phenylacetaldehyde & rose, floral, green & 0.10 & 0.68 & 1.33 & 2.11 & $40^{\mathrm{f}}$ & $\begin{array}{l}105^{\mathrm{i}}- \\
1,600^{\mathrm{h}}\end{array}$ \\
\hline 23 & 2-phenylacetic acid & floral, metallic, musty & 12.6 & 218 & 1,290 & 1,690 & & $2,500^{\mathrm{h}}$ \\
\hline 24 & 2-phenylethanol & floral, beer, rose & 110 & 278 & 579 & 874 & $240^{f}-750^{g}$ & $\begin{array}{l}40,000^{\mathrm{j}}- \\
125,000^{\mathrm{h}}\end{array}$ \\
\hline 25 & vanillin & vanilla & 45.9 & 448 & 754 & 1,040 & & \\
\hline 26 & 4-vinylphenol & chemical, medicinal & 90.0 & 2,340 & 2,540 & 4,210 & & \\
\hline
\end{tabular}




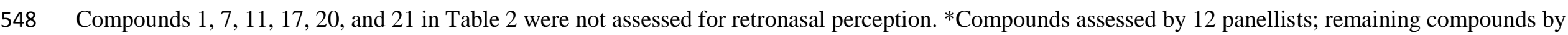
24 panellists. ${ }^{\text {aPatton }}$ (1964), ${ }^{\mathrm{b}}$ Rothe \& Thomas (1962), ${ }^{\mathrm{c}}$ Milo \& Grosch (1993), ${ }^{\mathrm{d}}$ Pittet, Rittersbacher, \& Muralidhara (1970), ${ }^{\mathrm{e}}$ Cerny \& Grosch (1993),

550 SSheldon, Lindsay, Libbey, \& Morgan (1971), ' ${ }^{\mathrm{g} O h l o f f ~(1978), ~ h M e i l g a a r d ~(1975), ~ i ́ S a i s o n ~ e t ~ a l . ~(2009), ~}{ }^{\mathrm{j} E n g a n}$ (1972). Full references in Appendix B. 

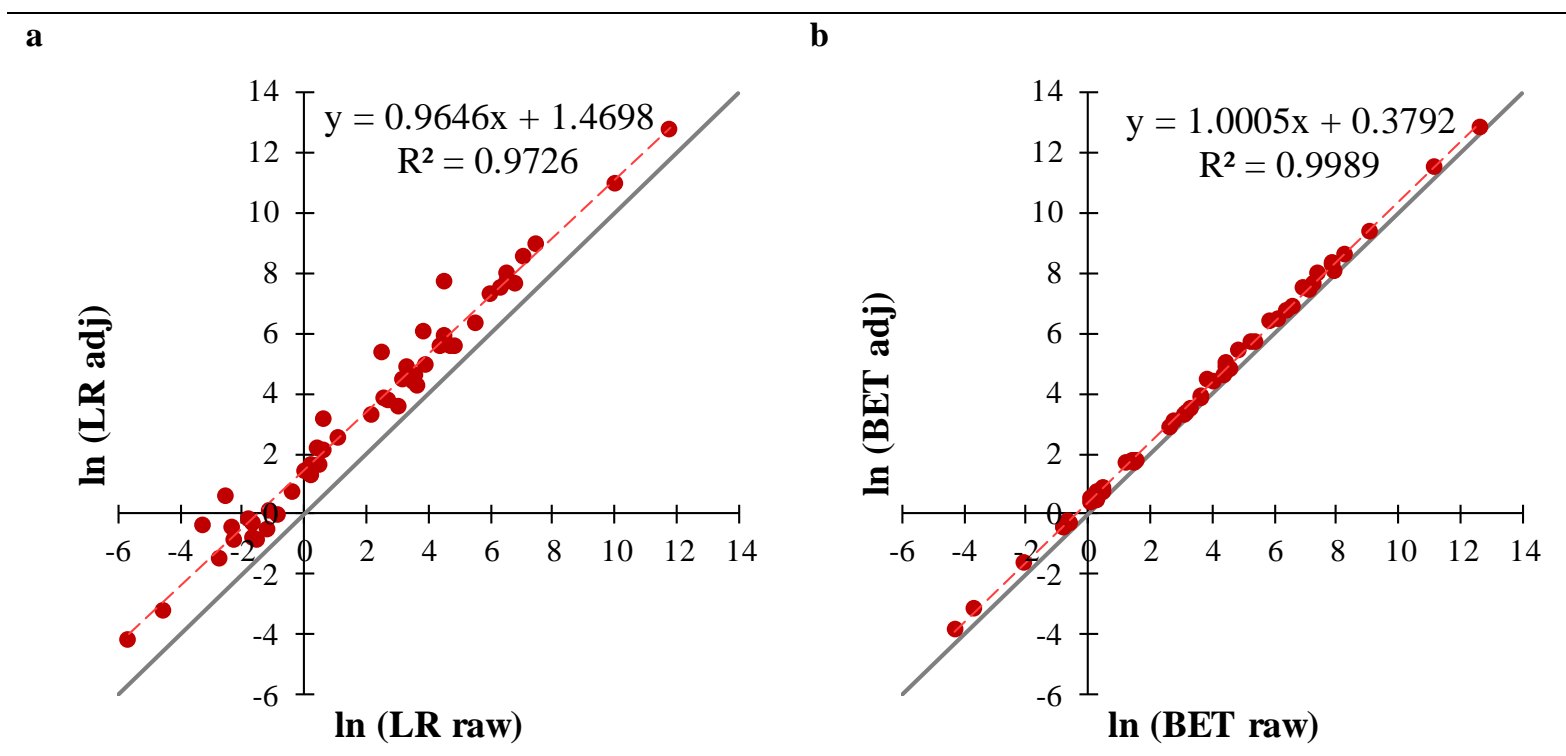

c

d
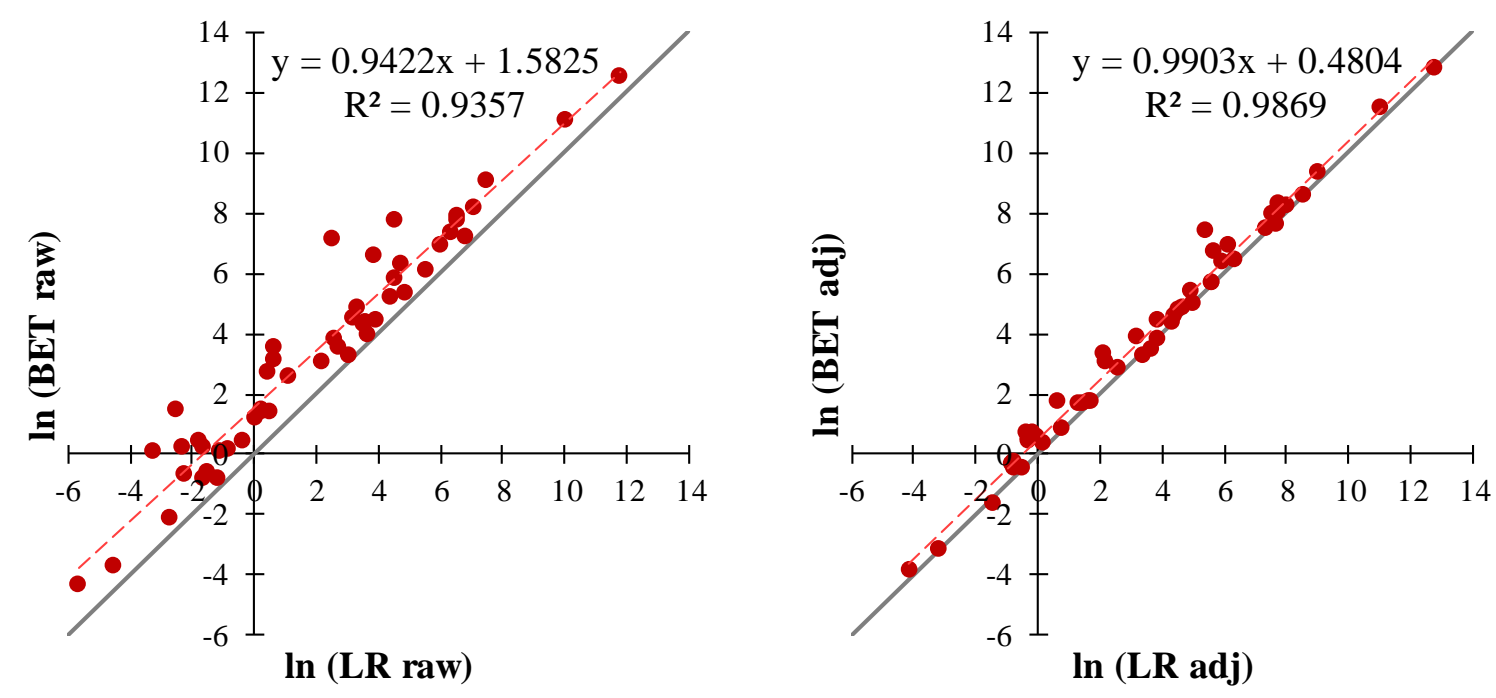

e

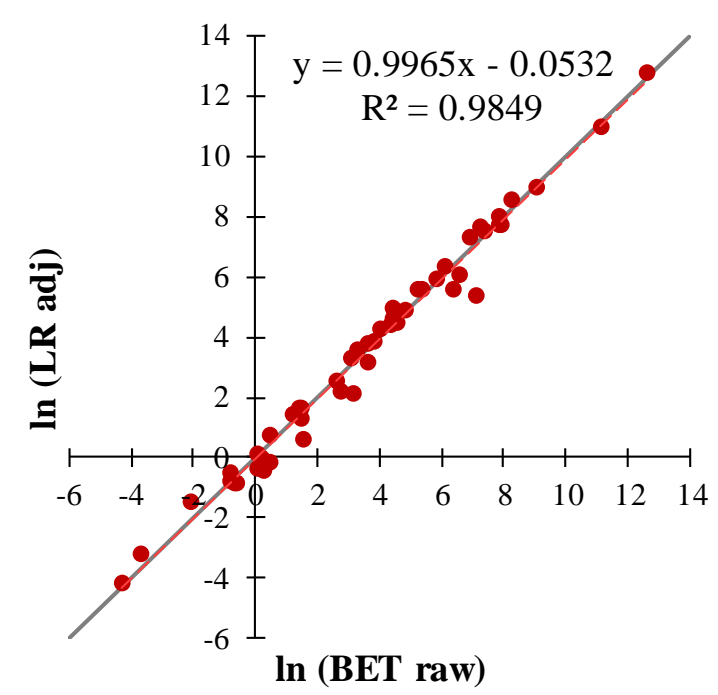

f

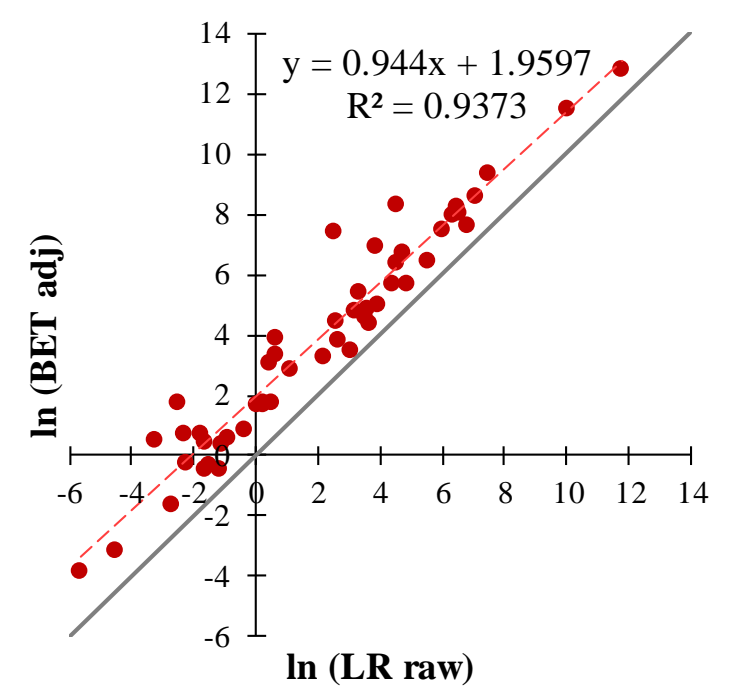


Figure 2

a

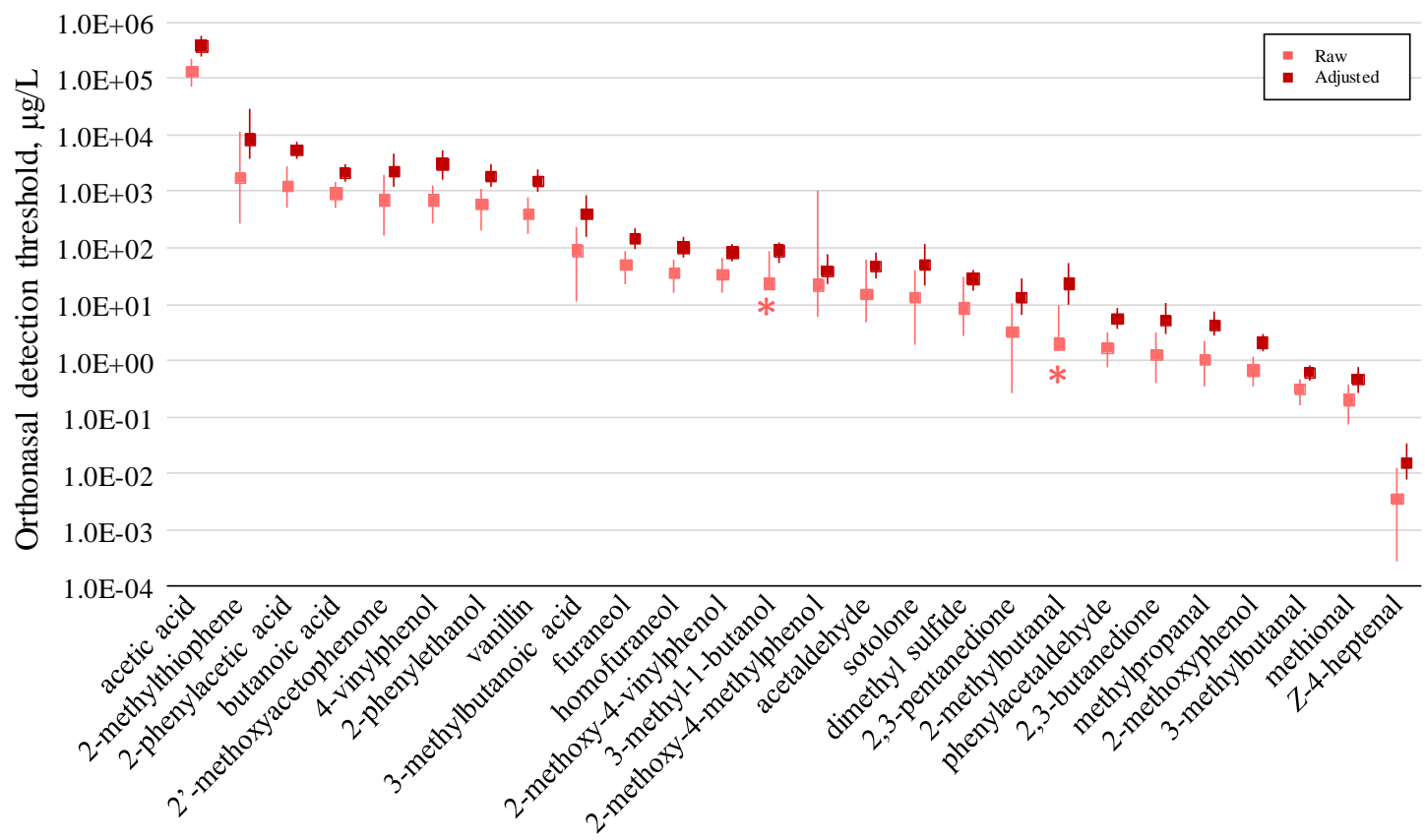

553

b

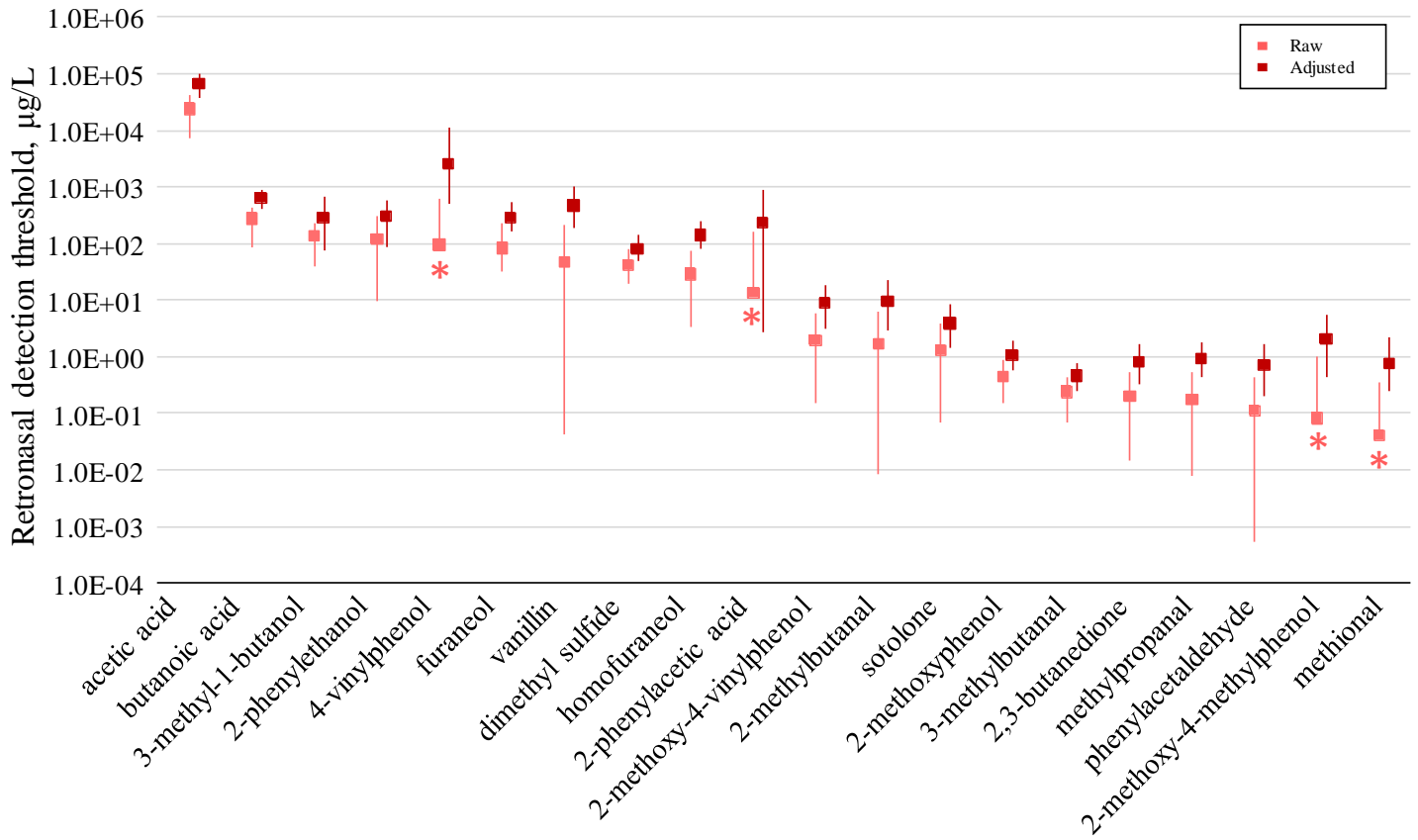

554 

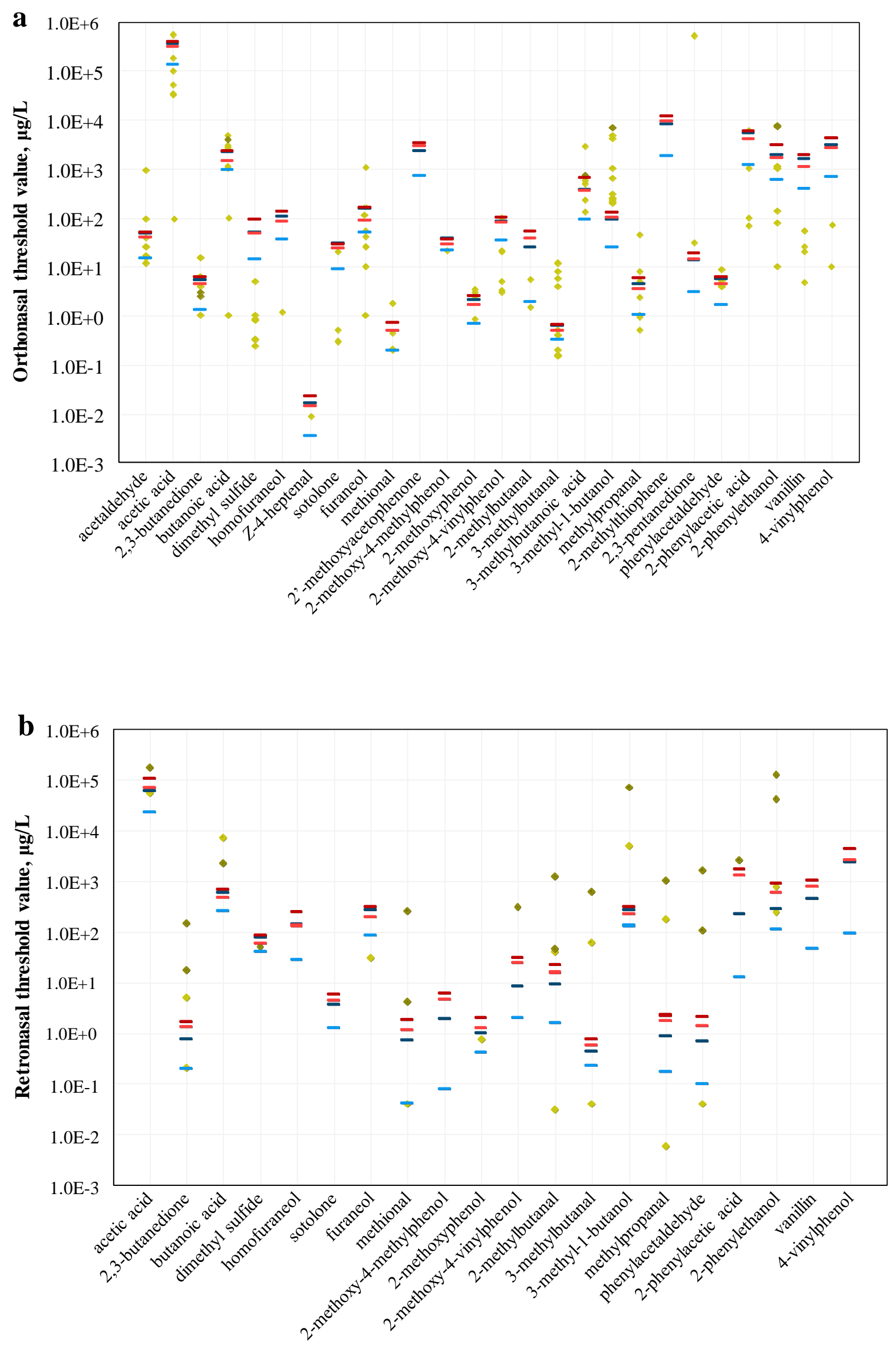
